\title{
TERMINOLOŠKI PROBLEMI U STANDARDIZACIJI NAZIVA INSTRUMENATA ANTIČKE GRČKE
}

Terminološke probleme pri istraživanju glazbe antičkih razdoblja nalazimo podjednako kod arheoloških i muzikoloških autora. Jedno od područja koje pati zbog nedostatka suradnje ovih dviju struka jest organologija. Čak i najkraći odlomci o glazbi antičke Grčke spomenut će liru, kitaru i aulos, no rijetko se koji autor detaljnije bavi terminološkim problemom žičanih instrumenata. Usporedbom opisa i ilustracija uočit ćemo velike nepodudarnosti unutar struka, pa čak i pojedinačnih djela. Najveći terminološki problem u klasificiranju žičanih instrumenata stvara termin lira koji se rabi generički i za pojedinačni instrument. Kako su odlomci o glazbi u literaturi obiju struka najčešće kratki i svedeni na osnovne podatke, rijetko se koji autor dotakne navedene polisemije, čime otežava čitateljevo razumijevanje. Terminološki problemi također nastaju zbog pogrešnih ili arheološkim nalazima nepotkrijepljenog opisivanja, ali i zbog krivih prijevoda. Neki autori antičke instrumente poistovjećuju sa suvremenim kako bi izbjegli posuđenice. U slučaju da ih koriste, one su rijetko u kurzivu, a umjesto njih (ili uz njih) koriste i druge termine. Ovim radom pokušat će se prikazati terminološki problemi triju navedenih instrumenata i njihovo porijeklo na temelju istražene arheološke i muzikološke literature u nadi da će pomoći standardizaciji termina kod prevoditelja te arheoloških i muzikoloških istraživača.

\section{Uvod}

Glazbu antičke Grčke proučavali su brojni arheološki i muzikološki stručnjaci. Prilikom ovih istraživanja instrumentalna se glazba najčešće smještala u drugi plan. Zbog određene suzdržanosti arheologa prema glazbi traganje za dokazima muzičkih aktivnosti svedeno je na minimum. Time su muzikolozi ograničeni na rad s već davno proučenim i istraženim nalazima kojima onda često samo pokušavaju pripisati neko novo značenje ili tumačenje. 
Literatura o grčkoj glazbi, a posebice njezinim instrumentima, često je nedovoljno precizna, nedorečena ili nejasna. Probleme najprije čini arheološka literatura čiji su autori nedovoljnoga glazbenog obrazovanja. Nedostatak suradnje, glazbenog znanja, pa čak i zainteresiranosti rezultirale su time da su istraživanja glazbe antičkih civilizacija skromna, često nestručna ili jednostavno nepostojeća. Golem arheološki opus o grčkoj kulturi detaljno se bavi elementima poput keramike ili likovnim umjetnostima, dok se glazba najčešće svrstava u manje istražena područja poput odjevnih predmeta ili onih svakodnevne uporabe ${ }^{1}$ te se najčešće na analizu prepušta muzikolozima koji se glazbom bave putem tekstova antičkih književnika.

Malobrojna arheološka literatura o glazbi nosi terminološku problematiku koja se nažalost susreće i u muzikološkoj literaturi. Iako su antički autori temelj ovog problema jer su instrumente klasificirali po posve drugačijim kriterijima, a nakon njih još više srednjovjekovni, pogreške se javljaju i u suvremenoj literaturi. Jedna od takvih pogreški kod arheoloških autora jest nazivanje puhaćih instrumenata s piskom frulama ili (još gore) flautama. Posebne probleme autorima obiju struka zadaju žičani instrumenti. Udaraljkaški instrumenti nasreću u manjoj mjeri trpe ovakve probleme jer se svi izvori njima manje bave.

Drugi izvor problema čine muzikolozi koji se za pisanje o instrumentima često koriste samo antičkim izvorima bez dovoljnog poznavanja arheoloških nalaza. Zbog nedostatka ili nedovoljno konkretnih dokaza proučavanje glazbā dalje prošlosti uvijek skriva opasnost prevelike slobode tumačenja koja na kraju rezultira i krivim baratanjem pojmovima i terminima.

\section{Lira i kitara}

Lira (gr. $\lambda \hat{v} \rho \alpha$; lat., njem., franc. lyra; engl. lyre; tal. lira) definira se kao ,ancient Greek stringed instrument plucked with plectrum, used to accompany singers (cp.KITHARA); term also used for similar plucked instruments of other civilizations, even if played without plectrum” (Jacobs 1961: 218) ${ }^{2}$; „starogrčki

\footnotetext{
Često se događa da pronađeni ostatci instrumenata u rukama arheologa nisu prepoznati kao glazbeni instrumenti te su kao nepoznati predmeti etiketirani kao kultni ili su protumačeni kao predmeti svakodnevne uporabe (za više vidi West 1992: 127).

2 „Žičani instrument antičke Grčke sviran trzalicom, korišten kao pratnja pjevača; termin koji se također rabi za slične trzalačke instrumente drugih civilizacija, čak i ako nisu svirani trzalicom" (autoričin prijevod).
} 
instrument sa žicama, po obliku i načinu sviranja vrlo srodan kitari s kojom se usporedno razvijao" (Andreis 1974a: 462); ili „string instrument whose strings are attached to a yoke which lies in the same plane as the soundtable and consists of two arms and a crossbar" (McKinnon i Wachsmann 1980: 397). ${ }^{3}$

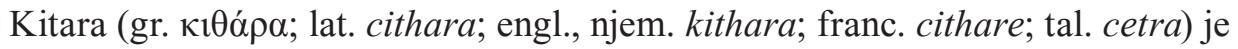
trzalački instrument srodan liri. Od lire se razlikuje gradnjom (jer umjesto kornjačina oklopa ima drvenu rezonantnu kutiju i šuplje drvene ručke (McKinnon 1980: 88; Tuksar 1992: 235-236)), ${ }^{4}$ ali i namjenom. „Dok je lira pretežno kućni instrument intimnog muziciranja, kitara je namijenjena javnim priredbama i natjecanjima" (Andreis 1974a: 325; usp. McKinnon 1980: 89; Tuksar 1992: 235-6).

Prvotna je vrsta lire za rezonantnu kutiju imala kornjačin oklop te je zbog toga nazivana chelys, grčkom riječi za kornjaču. ${ }^{5}$ Preostali oblici trzalačkih instrumenata (izuzev harfi) koji se javljaju u kasnijim razdobljima antike razvili su se iz chelysa te su skupno zvani generičkim terminom lira.

Lira je jedino glazbalo koje su Grci preuzeli iz mikenske, odnosno minojske kulture. Pločice s pismom linear B iz Pilosa sadrže izraze ki-nu-ra i ru-ra. Smatra se kako su oba naziva za žičane instrumente iz porodice lira. Prvi nije opstao na kopnenom području Grčke krajem brončanog doba (Franeschetti 2006: 8-9, Usp. Schlesinger 1911: 395). Drugi (ru-ra, lira) preuzima Homer. U grčkom je lira posuđenica iz jezika koji ne spada u indoeuropsku skupinu (Renfrew 1998: 246). Najranije se javlja u Homerovoj Himni Hermesu datiranoj u VI. stoljeće pr. Kr. (Landels 1999: 61; Renfrew 1998: 246-247). U Himni i drugim Homerovim djelima nalazimo i termine kitharis $^{6}$ te phorminx $^{7}$ (West 1992: 51). West smatra kako su potonji istoznačnice za vrstu lire, ${ }^{8}$ dočim Sendrey kitharis tumači kao termin za tehniku sviranja žičanog instrumenta koji u kasnijim razdobljima po-

\footnotetext{
„Žičani instrument čije su žice pričvršćene za jaram koji je u istoj ravnini s glasnjačom te se sastoji od dva kraka spojena prečkom" (autoričin prijevod).

4 Sličnu distinkciju nalazimo u The New Oxford Companion to Music (1983: 1106).

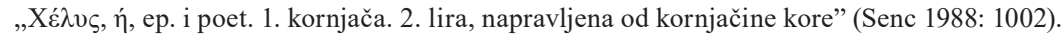

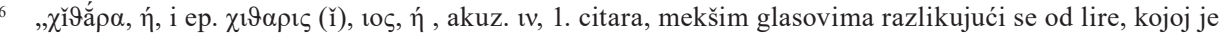
slična po obliku, ali je veća, sa četiri, kasnije sedam do devet žica. Hom. pjevač u nju udara samo za pripravu i da ispuni stanke, a ne da pjesmu uistinu prati. 2. zvek citare, zujanje žica" (Ibid: 513).

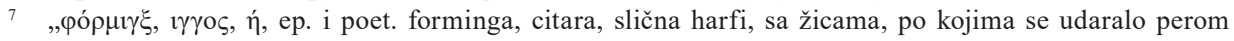
( $\pi \lambda \dot{\varepsilon} \chi \tau \rho \circ v)$; od $\chi 1 \vartheta \alpha \rho ı \varsigma$ se razlikuje samo veličinom" (Ibid: 988).

8 Termin phorminx dugo se koristio kao pjesnički naziv za veći broj žičanih instrumenata, pa pretpostavljamo da je West zaključio kako Homer koristi jedan organološki termin te njegov poetski ekvivalent.
} 
staje termin za instrument (Sendrey 1974: 292; usp. Renfrew 1992: 247). Riječ kitharā u grčkom se jeziku javlja tek u 5. stoljeću (West 1992: 51). Homer i drugi antički književnici nepouzdani su izvori za organologiju jer se nisu držali stroge terminologije, već su se prepuštali pjesničkoj slobodi. Autori nakon Homera rabe lyrā, kitharā i barbitos za različite instrumente, a prvi ujedno za cijelu porodicu instrumenata (Renfrew 1998: 246-247; usp. West 1992: 50). ${ }^{9}$ Termin phorminx koji je dugo bio pjesnički izraz za žičane instrumente tipa lire u ovim se stoljećima više ne upotrebljava (Ibid: 51).

Srednjovjekovni autori preuzimaju grčko organološko nazivlje, no ono dobiva novo značenje. Latinski termin lyra označava kruškoliki gudački instrument s polukružnim otvorima na tijelu (Sachs 1979: 247), dočim se kitara na prijelazu u srednji vijek postupno transformirala u citru, slijedom čega preuzima nazive cistra (franc.), cittern (engl.), sister (njem.) ili cetra (tal.) (Reinhard 1986: 1452; Tuksar 1992: 235; Winternitz 1961). Renesansni i barokni autori u svojim organološkim djelima spominju starogrčke pretke suvremenih glazbala, ali istraživačima antičkog nazivlja svojom terminologijom dodatno otežavaju posao. Praetoriusova Syntagma musicum (21619) sadržava poglavlja Lyru, Testudo. Laute i Cithara, gdje se pod prvim naslovom izlaže o više srodnih gudačkih instrumenata, pod drugim glazbala tipa lutnje (,Di Lauten (Testudo, Chelys, Italis Liuto)"), a pod trećim kitara, odnosno citra. Baš kao i Praetorius, Kircher (1650: 476 i d., koji se u svojem djelu vodi za Mersenneom (1636), latinski naziv testudo veže uz lutnju koju razlikuje od citre po tome što joj stražnja ploha korpusa nije izbočena, već ravna, dočim termin lyra vezuje uz gudačka glazbala te ga rabi za specifične vrste poput Lyre Barberine i Lyre Argolice (Ibid: 66). ${ }^{10}$

U djelima hrvatskih renesansnih i baroknih intelektualaca suvremeni su muzikolozi popisivači uočili zbrku kod termina kitara i lira. Fraust Vrančić (1595) ra-

\footnotetext{
9 „Ostaje, onda, da se u državi mogu upotrebljavati samo lira i kitara. A u poljima bi mogla biti i koja siringa da sviraju pastiri” Platon 399d; „Slično se dogodilo i s mnogim drugim drevnim glazbalima, kao što su lidijska harfa i mnogostrana lira (grč. ßó $\rho \beta \imath \tau$ ) ” Aristotel: Politika 1340; „Epsko, dakle, i tragičko pjesništvo, uz to komedija i sastavljanje ditiramba, te najveći dio sviranja na fruli i citri, sve se to, govoreći uopćeno, može označiti kao oponašanje" Aristotel: O Pjesničkom umijeću 1447a (original ne spominje

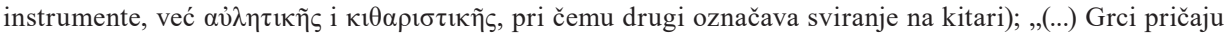
kako je Hermes izumio liru, a Apolon kitaru." Pauzanija 5.14.8.

10 Slično nalazimo kod Mersennea koji lirom naziva kololiru (Prop. X), lirone, tj. basovsku verziju lire da braccio (Prop. VIII) i Liru Barberinu (Prop. XI). Nejasnoće kod Kirchera stvaraju i nazivi Chelys maioris, Chelys hexachorda, Lyra dodekachorda, Chelys minor i dr. koji smješteni uz ilustracije gudaćih instrumenata (1650: 68) čitatelja upućuju na isto porijeklo lutnje i porodice violina.
} 
zlikuje guzlé kao istovrijednicu latinske, odnosno talijanske cithare i gußle kao ekvivalent latinske lyre (Tuksar 1976). Slijedi ga Jakov Mikalja koji u svojem hrvatsko-talijansko-latinskom popisu ,jezičnog blaga” (1649-51) çitari pridodaje talijanski korelat cetera, naziv za glazbalo tipa gitare s kruškolikim korpusom. Gusli prevodi na talijanski kao liru ili cetru, odnosno na latinski kao Fides, Lyru i cytharu (Ibid. 1980). Kasniji se jezikoslovci (J. Habdelić 1670., A. Della Bella 1728., I. Belostenec 1740.. i A. Jambrešić 1742.) (Vidi Tuksar 1992) u natuknicama o kitari ili liri i njihovim prijevodima vode za prethodnim izvorima. Istoznačnice citara, cetra ili četra u ovim se djelima javljaju kao sličnoznačnice termina lira. Ona pak označava antički instrument, gudaće glazbalo europske umjetničke glazbe ili dalmatinsko folklorno glazbalo (Ibid: 235-257). Tuksar upravo kod Belostenca (čiji je popis glazbenog nazivlja najopširniji) ističe nejasnoće kod spomenutih termina i njihovih prijevoda, posebice kod onih koji bi mogli upućivati na gudaća glazbala. Ipak na temelju natuknica o načinu sviranja zaključuje kako je pri svakom spomenu citare i lire riječ o trzalačkom instrumentu (Ibid: 454-455).

Istraživanja Danice ilirske i djela I. Kukuljevića Sakcinskog što ih je provela Dubravka Franković (1986) pokazuje nam kako literatura ilirskih autora nosi breme svojih prethodnika. Prvi pokušaji stvaranja hrvatskog glazbenog nazivlja u Kuhačevu Katekizmu glazbe nastalom prema onome J. C. Lobea sadrži natuknice: „,indra, citra, skripka, (slov. pentek), die Zither” (115) i ,lira, (grčki simbol sviju glazbala), die Lyra (griechisches Symbol aller Musikinstrumente)" (117).

Ovaj kratki i nepotpuni povijesni pregled djela odabranih inozemnih i domaćih autora do 20. stoljeća jasno upozorava na korijene terminoloških problema suvremenika. Sve natuknice u njima (kao i u preostalim djelima za čija je izlaganja ovaj rad ograničen) iznose izmjene koje su starogrčki instrumenti lira i kitara i njihovi nazivi doživjeli. Gotovo sva djela od antike do 20. stoljeća sadrže termin citara ili citra koji najčešće upućuje na tip instrumenta koji se razvio iz starogrčke kitare ili na gitaru. Lira je gotovo uvijek vezana uz gudaća glazbala, a chelys uz trzalačka glazbala izbočenog korpusa, tj. lutnje. Suvremeni autori često pogrešno preuzimaju srednjovjekovno nazivlje u djelima o antici (npr. citara za kitaru). Njihova je najveća boljka ipak višeznačnost riječi lira.

Suvremenu literaturu o starogrčkim instrumentima moguće je razdvojiti na onu glazbenih stručnjaka i onu arheologa. Potonjih je znatno manje. Arheološki au- 
tori koji se glazbom bave višeznačnost termina lira detaljno objašnjavaju, kao i razliku lire (u užem smislu riječi) i kitare (Younger 1998: 14. i d; West 1992: 50). Samo pojedini muzikološki autori detaljno tumače razliku između lire i kitare. Ispravan opis i razlikovanje nalazimo u djelima Curta Sachsa (1943, 1962, 1980). U drugoj stručnoj muzikološkoj literaturi opisi dvaju instrumenata uistinu variraju.

Terminološki se problemi dodatno kompliciraju u djelima hrvatskih autora. Ponajprije zbog toga što imamo ,kroničan nedostatak referentne stručne literature na hrvatskom jeziku" (Kiš Žuvela 2014: 5). Glazbala kojima se bavi ovaj rad spominju se prvenstveno u organološkim (Odak 1956, Spiller 1996), terminološkim (Franković 1986, Tuksar 1992) ili etnomuzikološkim radovima (Širola 1933, 1940) i u manjoj mjeri povijesnim pregledima (Andreis 1974, Pavlović 1974, Tuksar 2000). Potonjih je tek šačica i antikom se bave usputno, zbog čega ne objašnjavaju, pa čak i ne spominju navedenu višeznačnost koja buni čitatelje. Iznimku među hrvatskim autorima čine Spiller čija je podjela kordofonih glazbala detaljna (1996: 373) i Tuksar (1992).

\section{Aulos}

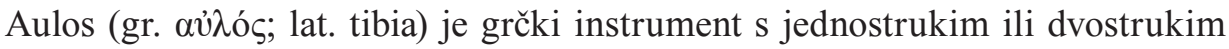
piskom. Najčešće se javlja u paru, a sastoji se od cilindričnih ili koničnih cijevi različitih veličina (McKinnon 1980a: 699; usp. Kovačević 1984: 83; Schlesinger

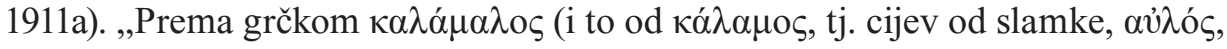
tj. sviraljke)" (Širola 1933: 44) u srednjem vijeku izvodi se latinski calamellus, tj. srednjovjekovno nazivlje za srodne instrumente šalmaj, shalm, chalumeau, schalmei, hautbois (Schlesinger 1911a: 917). Instrument i naziv aulos vezan je uz antičko razdoblje te se puno rjeđe spominje u literaturi nakon antike.

Iako u grčko-hrvatskom rječniku uz natuknicu aulos stoji „svaka svirala, osob. frula, (...)" (Senc 1988: 137), a kod Klaića ,grč. frula, svirala, dvojnice (...)" (Klaić 1990: 120), većina suvremenih autora aulos ne izjednačava s frulama i flautama. ${ }^{11}$

\footnotetext{
11 Iznimke su odlomak Michelsova Atlasa glazbe I koji navodi kako je Marsija „svirač aulosa /tj. frulaš/” (2004: 171), zatim The New Oxford Companion to Music koji za aulos piše „Lat.: tibia; u suvremenim se jezicima tradicionalno prevodi kao 'frula' (...)" (1983: 116; autoričin prijevod).
} 
Mnogi autori žele izbjeći posuđenice, zbog čega rabe opisne termine odnosno nazive suvremenih instrumenata. Umjesto posuđenice (ili uz nju) koriste raznolike termine: frula, svirala (Sachs 1943: 138), oboa, dvostruka oboa (Sachs 1943: 138-139; West 1992: 387), šalmaj (Michels 2004: 159), dvostruka oboa oštrog, prodornog zvuka (Apel i Daniel 1960: 12; Wiora 1967: 59, 74) i sl. U suvremenoj literaturi o aulosu česta je nestandardiziranost unutar pojedinog djela. Najčešće se javljaju termini aulos ili auloi, no pojedinci uz njih rabe druge termine kao sinonime i nude raznolike prijevode grčkog naziva. Termin pipe (tj. svirala) koji Sachs smatra najboljim prijevodom (1943: 138) (iako istovremeno uz njega koristi i termin dvostruka oboa (Ibid: 139)) West kritizira kao nedovoljno informativan te savjetuje da bi se aulos trebao definirati kao oboa (1992: 82), zbog čega ga povremeno naziva udvostručenom, tj. dvostrukom oboom (,,paired oboe”, Ibid: 387). Sendrey i Wiora u poglavlju o glazbi antičke Grčke rabe termin aulos. Isti instrument $u$ poglavljima o drugim antičkim civilizacijama nazivaju dvostrukom oboom ili sviralom s dvostrukim piskom usprkos tomu što i sami navode kako je riječ o istom instrumentu (Wiora 1967: 60). Michels u poglavlju o grčkoj glazbi koristi aulos i dvostruki aulos (doppelaulos), u poglavlju o Mezopotamiji naziva ga šalmajem, a kod Feničana ga navodi kao ,dvostruki aulos (dvostruki šalmaj)" (2004: 163). Za razliku od navedenih autora, Younger ovakav tip instrumenta naziva aulosom u svim civilizacijama (1998: 29).

Razlikujemo aulose s jednostrukim jezičkom (iako su njihovi prikazi poprilično oskudni) koji su srodni današnjem klarinetu te aulose s dvostrukim jezičkom (koji su najreprezentativniji u klasičnom razdoblju) srodne današnjoj oboi (Schlesinger 1911a: 917; Širola 1933: 44 i d). Nevezano uz način sviranja i vrstu piska, na gotovo svim prikazima aulos se sastoji od dvije cijevi. Pojedini autori aulos s dvije cijevi nazivaju dvostrukim. Drugi mu pridodaju grčki prefiks $d i$. Broj cijevi stvara terminološku zbrku jer većina autora pod terminom aulos već podrazumijeva dvostruki aulos, tj. glazbalo s dvije cijevi (kako ga uostalom i opisuju). Arheološki autori i pojedini muzikološki pod terminom aulos podrazumijevaju samo jednu cijev instrumenta (vjerojatno zato što grčka riječ aủ označava prvenstveno cijev, tj. sviralu), dočim cijeli instrument koji karakterizira istodobno sviranje dviju cijevi nazivaju diaulosom ili dvostrukim aulosom, tj. množinom auloi (Landels 1963, 1964, 1968, 1999, ${ }^{12}$ Schelsinger 1970, Youn-

\footnotetext{
12 Landels grčki auloi rabi za dvostruki aulos, za više jednocijevnih aulosa i za više nalaza jedne cijevi aulosa.
} 
ger 1998, West 1992). Muzikološki izvori rijetko koriste diaulos ${ }^{13}$ i ne koriste množinu, ${ }^{14}$ već instrument $\mathrm{s}$ dvostrukom cijevi jednostavno nazivaju aulosom. Slijedom toga ispostavlja se da je prefiks (bilo grčki bilo hrvatski) nepotreban.

\section{Zaključak}

Prema svemu dosada iznesenom terminološki problemi nazivlja instrumenata antičke Grčke svode se na sljedeće:

Arheološkim dokazima utvrđeno je da su nazivi frula, flauta ili svirala zastarjeli, neprikladni ili nedovoljno precizni nazivi za aulos. Iako je aulos poželjno opisati i moguće (točno) usporediti sa suvremenim instrumentima kako bi ga se približilo današnjem čitatelju, smatramo da je prevođenje grčke posuđenice kojom ga nazivamo suvišno. Poseban je oprez potreban pri istodobnoj uporabi termina aulos i diaulos / dvostruki aulos jer navodi čitatelja na pomisao kako je aulos instrument s jednom, a diaulos s dvije cijevi, što često nije slučaj u kontekstu u kojemu se termin nalazi.

Organološki nazivi koje nalazimo u djelima srednjovjekovnih, renesansnih i baroknih glazbenih teoretičara za instrumente koji su se razvili iz starogrčke lire, kitare i aulos, tj. citra, citara, šalmaj i drugi također su neprimjereni kada se piše o antičkoj glazbi.

Anglosaksonski autori razlikuju starogrčko glazbalo lyre i renesansni gudaći instrument liru. $\mathrm{U}$ hrvatskom su jeziku oba navedena instrumenta istog naziva. ${ }^{15}$ Usto se termin lira koristi i za tradicijski kordofoni instrument liricu. Time se višeznačnost riječi lira dodatno povećava. Autori djela koja se isključivo bave antikom moraju barem spomenuti dvoznačnost riječi lira, dočim bi organološka djela šireg opsega trebala jasno razdvojiti termine za starogrčki trzalački, renesansni gudaći ili udaraljkaški instrument. S obzirom na to da su se navedeni ustalili u hrvatskom jeziku pod terminom lira, bilo bi ih teško imenovati

13 Iznimka je Širola. (1940: 47-48).

14 Iznimke su Sendrey i Wiora.

15 „Lira, 1. Starogrčki instrument sa žicama, po obliku i načinu sviranja vrlo srodan kitari s kojom se usporedo razvijao (...), 2. Gudački instrument koji je u toku XVI. st. dosegao doba svog puno razvitka. Imao je više žica od kojih su neke stajale izvan hvataljke i vršile funkciju borduna. Smatra se pretečom violine (...)" (Andreis 1974a: 462). 
drugačije, zbog čega autorima samo preostaje preciznije baratanje terminima i smještanje u jasan kontekst. Kao prijedlog za razlikovanje lire kao pojedinačnog instrumenta i njezina generičkog značenja autori mogu prihvatiti ideju arheologa Renfrewa i Youngera koji rabe složenicu chelys-lira.

U navedenoj hrvatskoj literaturi očigledan je nedostatak normiranosti nazivlja antičkih instrumenata. Jedni rabe tuđice u kurzivu (Odak), drugi ih prilagođavaju hrvatskom jeziku pa phorminx, tj. forminks postaje forminga (npr. Tuksar 2000: 12), a sirinx, tj. sirinks postaje siringa i sl. (npr. *** 21977: 358).

Suradnja arheologa i muzikologa, ali i klasičnih filologa pri klasifikaciji antičkih instrumenata može samo pridonijeti jasnijem razumijevanju teksta, a time i kvaliteti te točnosti daljnjih istraživanja.

\section{Literatura:}

ANDREIs, JosIP. 1974. Glazba u životu izvaneuropskih civilizacija Bliskog i Dalekog istoka; Antička glazbena kultura. Povijest glazbe 1, Liber. Zagreb. 21-74.

ANDREIs, Josir. 1974a. Kitara; Lira. ME, 2. Ur. Kovačević, K. Jugoslavenski leksikografski zavod. Zagreb. 325, 462.

Apel, Willi; Daniel, Ralph T. 1960. Aul os; Kithara; Lyra; lyre. The Harvard Brief Dictionary of Music. Amsco Music Publishing Company. New York. 12, 60, 64.

Aristotel. 1988. Politika (preveo Tomislav Ladan). Globus - Liber. Zagreb.

Aristotel. 2005. O pjesničkom umijeću (preveo Zdeslav Dukat). Školska knjiga. Zagreb. Franceschetti, Adele. 2006. Musici e strumenti musicali alle corti Micenee. Colloquium Romanum, Atti del XII colloquio internazionale di micenologi, Roma 20-25 Febbraio 2006. Ur. De Miro, Ernesto; Godart, Louis; Negro, M.; Sacconi, Anna. Fabrizio Serra. Rim.

Franković, Dubravka. 1986. Glazbena terminologija u „Slovniku umjetnikah jugoslavenskih" Ivana Kukuljevića Sakcinskog. Arti musices 17/1. 3-74.

Homer. 2003. Ilijada (preveo Tomo Maretić). Nakladni Zavod Matice Hrvatske. Zagreb. Homer. 1987. Odiseja (preveo Tomo Maretić). Nakladni Zavod Matice Hrvatske. Zagreb.

JaCobs, Arthur. 1961. Aulos; Kithara; Lira; Lyre. A New Dictionary of Music. Cassell. London. 24, 196, 211, 218.

Kircher, Athanasius. 1970. Musurgia Universalis. Georg Olms Verlag. Hildesheim. 
Klaić, Bratoluub. ${ }^{2}$ 1990. Rječnik stranih riječi - tuđice i posuđenice. Nakladni zavod Matice hrvatske. Zagreb.

KovaČEvić, Krešimir. 1974. Aulos. ME, 1. Ur. Kovačević, K. Jugoslavenski leksikografski zavod. Zagreb. 83.

Kuhač, Franjo Ksaver. 1889. Katekizam glazbe (po J. C. Lobeu). Naklada Akadem. knjižare Lav. Hartmana. Zagreb.

Landels, John G. 1963. The Braur on Aul os. The Annual of the British School at Athens 58. 116-119.

Landels, John G. 1964. Fragment s of Aul oi Found in the Athenian Agora. Hesperia: The Journal of the American School of Classical Studies at Athens 33/4. 392-400.

Landels, John G. 1968. A Newl y Discovered Aul os. The Annual of the British School at Athens 63. 231-238.

Landels, John G. 1999. Music in ancient Greece and Rome. Routledge. London.

McKinnon, James W. 1980. Kit hara. NgroveD, 7. Ur. Sadie, S. Macmillan Publishers Limited. England. 88-89.

McKinnon, James W. 1980a. Aulos. NgroveD, 2. Ur. Sadie, S. Macmillan Publishers Limited. England. 699-702.

McKinnon, James W.; Wachsmann, Klaus. 1980. Lyre. NgroveD, 7. Ur. Sadie, S. Macmillan Publishers Limited. England. 397-401.

Mersenne, Marin. 1636. Harmonie universelle, contenant la théorie et la pratique de la musique. Libri IV.

Michels, Ulrich. 2004. Atlas glazbe I, sistematski dio i povijest glazbe od početaka do renesanse. Golden marketing - Tehnička knjiga. Zagreb.

OdAK, Krsto. 1956. Poznavanje instrumenata. Muzička naklada. Zagreb.

Pauzanija. 1901. Graeciae Descriptio. Liber quintus. O. R. Reisland. Leipzig.

PAvlović, Mirka. 1974. Grčka Muzika. ME, 2. Ur. Kovačević, K. Jugoslavenski leksikografski zavod. Zagreb. 15-21.

Platon. 1997. Država (preveo Martin Kuzmić). Naklada Jurčić d.o.o. Zagreb.

Praetorius, Michael. ${ }^{2}$ 1619. Syntagmatis musici tomus secundus. De Organographia. Wolfenbüttel.

Reinhard, Kurt. 1986. Cister. MGG. 8. Kassel. 1451-1458.

Sachs, Curt. 1943. The History of Musical Instruments. W. W. Norton \& Company, Inc. New York.

SAChs, CuRT. 1979. Real-lexikon der Musikinstrumente: zugleich ein Polyglossar für das gesamte Instrumentengebiet. Georg Olms Verlag. Hildesheim - New York.

SACHS, CurT. 1980. Muzika starog sveta na istoku i zapadu; uspon i razvoj. Univerzitet umetnosti u Beogradu. Beograd. 
Schlesinger, Kathleen. 1911. Cithara. Encyclopaedia Brittanica. 6. Encyclopædia Britannica, Inc. 395-411. https://en.wikisource.org/wiki/1911_Encyclop\%C3\%A6dia_Britannica/Cithara (pristupljeno 21. studenog 2018.)

Schlesinger, Kathleen. 1911a. Aulos. Encyclopaedia Brittanica. 2. Encyclopædia Britannica, Inc. 917-920. https://en.wikisource.org/wiki/1911_Encyclop\%C3\%A6dia_Britannica/Aulos (pristupljeno 21. studenog 2018.)

Senc, StjePan. ${ }^{2}$ 1988. Grčko hrvatski rječnik. Naprijed. Zagreb.

Sendrey, Alfred. 1974. Music in the Social and Religious Life of Antiquity. Associated University Presses, Inc. Cranbury, New Jersey.

SPILler, Felix. 1996. Muzički sustav: teorija, harmonija, polifonija, muzički oblici, povijest muzike,instrumenti, interpretacija. Vlastita naklada. Zagreb.

ŠIrola, BožIDAR. 1933. Sopile i zurle. Narodna starina 12/30. 1-64.

ŠIrola, BožIDAR. 1940. Hrvatska narodna glazba. Pregled hrvatske muzikologije. Matica hrvatska. Zagreb.

Tuksar, Stanislav. 1976. Hrvatska glazbena terminologija u „Rječniku” Fausta Vrančića (1595). Arti musices 7. 41-59.

Tuksar, StAnislav. 1983. Nazivlje glazbenog instrumentarija u gazofilaciju (1740) Ivana Belostenca (1740). Varaždinski zbornik: zbornik radova sa Znanstvenog skupa održanog u Varaždinu od 1. do 3. listopada 1981. godine povodom obilježavanja 800. godišnjice grada. Ur. Mohorovičić, A. Jugoslavenska akademija znanosti i umjetnosti, Zavod za znanstveni rad u Varaždinu. Varaždin. 441-460.

Tuksar, StAnisLav. 1992. Hrvatska glazbena terminologija u razdoblju baroka. HMD - MIC. Zagreb.

Tuksar, Stanislav. 2000. Kratka povijest europske glazbe. Matica hrvatska. Zagreb.

West, M. L. 1992. Ancient Greek Music. Clarendon Press. Oxford.

Winnington-Ingram, R. P. ${ }^{2} 2001$. Greek music (ancient). NgroveD, 7. Ur. Sadie, S. Macmillan Publishers Limited. England. 700-781.

Winternitz, Emanuel. 1961. The Survival of the Kithara and the Evolution of the Cittern. A Study in Morphology. Music, Libraries and Instruments. Ur. Sherrington, U. i Oldham, G. Hinrichsen Edition. Pariz - New York.

Wiora, Walter. 1967. The four ages of music. W. W. Norton \& Company, Inc. New York. Younger, John G. 1998. Music in the Aegean Bronze Age. Paul Åstrőms Főrlag. Jonsered. The New Oxford Companion to Music. 1983. Ur. Arnold, D. Oxford University Press. Oxford - New York.

***. ${ }^{2}$ 1977. Siringa. ME, 3. Ur. Kovačević, K. Jugoslavenski leksikografski zavod. Zagreb. 358 . 


\section{Terminological problems of Ancient Greek instrument terms}

\section{Abstract}

Terminological problems equally arise in archeological and musicological research of ancient Greek music. One field that suffers from this lack of collaboration is organology. Even the shortest paragraphs on ancient Greek music will mention the lyre, the kithara, and the aulos but only a few authors deal with the barely noticeable terminological problem of the string instruments in detail. By comparison of descriptions and illustrations of the latter, we notice great incompatibility. The biggest terminological problem in classifying string instruments is the term lyre that is used generically and for a specific instrument. Since the paragraphs on ancient music in archeological and musicological literature are short and reduced to basic information, this polysemy is rarely mentioned. This makes the reader's and the researcher's understanding of the subject difficult. We find terminological problems due to wrong or uncorroborated depictions, but also because of the wrong translations from Greek and other languages. Some authors equate ancient instruments with contemporary to avoid loan-words but instead use various terms. When they use loan-words they rarely italicize them. This work will try to clarify the classification of ancient Greek string instruments by using definitions based on the studied literature and hopefully it will serve for terminology standardization that can be used by translators and researchers.

Ključne riječi: arheologija, lira, kitara, aulos

Keywords: Archeology, lyre, kithara, aulos 